\title{
Experimental production of penicillin in Kunming in the early 1940 s
}

\author{
Dingding Xu \\ Institute for the History of Natural Science, Chinese Academy of Sciences, Beijing 100010, China
}

In 1928, Sir Alexander Fleming made the profound discovery of penicillin. After approximately 10 years, the Oxford team, including Sir Howard Florey, Professor Ernst Chain, and their assistants, made progress in the methods of penicillin production, especially in extraction, purification, and assay. They then published their research in detail in The Lancet on August 16, 1941.

Threatened by the Luftwaffe bombings, Florey came to the United States to seek opportunities for the mass production of penicillin. Aware of the possible massive usage of penicillin during the war, the Committee of Medical Research of the U.S. government organized research institutes (e.g., North Region Research Laboratory) and pharmaceutical corporations (e.g., Merck, Squibb, and Pfizer) to study and produce penicillin in an industrial scale. From 1941 to 1944 , and supported by the War Production Board, the industrialization was completed, and penicillin became a common antibiotic applied to both military and everyday life during the latter half of the Second World War.

After learning about the achievement of the Oxford team, Chinese scientists became interested in this magical drug and attempted to produce it themselves. The major research institute designated for this purpose is the National Epidemic Prevention Bureau (NEPB), which generated successful results.

As the chief institute for the prevention of infectious diseases and the pro- duction of biological products in China, the NEPB was established in Peking in 1919 and was moved to Nanking in 1935. After the Anti-Japanese War in 1937, the Bureau evacuated to Changsha in 1938. In Changsha, renowned Chinese microbiologist Tang Feifang was appointed the director of the Bureau. Tang transferred the Bureau to Kunming in 1939. Led by Tang Feifang, the NEPB built a new laboratory and recruited new staff members, including scientists and technicians. Thus, a small group was formed for microbiological and immunological research even in the rear area of the war.

In Kunming, Tang suggested to set up weekly seminars on thesis presentation from foreign academic journals. In one of these seminars in the autumn of 1941, they read about the Oxford team's work, which motivated them to manufacture penicillin by themselves.

According to history, the entire experimental production of penicillin comprised two steps. The first step involved finding and selecting the appropriate Penicillium strain. From the winter of 1941 to 1945 , they compared 30 local strains and more than 10 foreign strains, including the NRRL 832 and NRRL 1229-B21. These strains were used in mass production in the United States at the time. The Chinese scientists found that the local No. 22 was the best strain and used it in their subsequent experiments. At the same time, they continued to focus on foreign thesis and main- tained communication with Dr. Tung Tsun, who was studying penicillin in the United States at the time.

The second step involved the extraction and purification of penicillin, which was completed mainly by Chu Chiming and Wong Youwei from the NEPB, Fan Chingseng from the Chinese Blood Bank, and Tang Feifang himself. As for the major technical flow and the size of experiment, the work of the NEPB team was similar to that of the Oxford team,

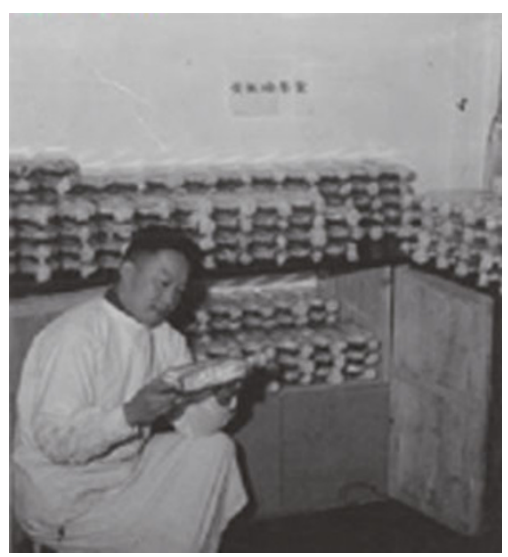

Figure 1. Manufacture of penicillin at the NEPB

but the NEPB researchers adopted some developed technologies. For example, to grow the mould, they used Sabouraud medium to cultivate spore and inoculated it with peanut oil to the corn steep liquor medium containing traces of Zinc ion. As an effective improvement, they invented the oil inocu- 
lation method, whereas the corn steep liquor and the addition of Zinc ion were based on the mass production procedure in the United States.

However, due to the extreme lack of the necessary apparatus and equipment, they encountered obstacles, which compelled them to adjust or simplify the methods based on local conditions, especially in production. For instance, given the shortage of adsorption column of alumina used for the concentration of penicillin, the NEPB researchers simplified the extraction method. They used two times amyl acetate and two times ether to extract penicillin, and adopted ethyl acetate instead of amyl acetate due to the unavailability of such material at the beginning. They modified the agar cup method of qualitative assay to replace the cylinder plate method used for quality test due to the inadequate precision of self-made cylinder when they attempted to imitate the cylinder cup method to assay titration of penicillin at different stages. Without a freeze dryer, the production process had to be suspended at the end of purification despite the achievement of the extraction solution. Thus, Wong Youwei designed a simple instrument and produced it in a factory. Finally and fortunately, it fulfilled the requirements.

The first batch of five ampoules of penicillin was produced on September 5 , 1944. Each bottle contained 5,000 Oxford units, which the total weight of penicillin was approximately 140 milligrams. They sent one sample to Oxford University (for examination by Norman Heatley) and another to Wisconsin University. Both institutions sent their congratulations and encouragement. The second batch of production in clinical tests generated good results in Huidian Hospital and Kunhua Hospital in Kunming. From 1944 to 1945, the NEPB continued to produce small amounts of penicillin with some improvements. Given their performance, a small suit of equipment from the American Bureau for Medical Aids to China was sent to them in the spring of 1945, which was installed in Peking after the Anti-Japanese War. This pilot plant, which probably produced the first batch of penicillin in 1947, became the cradle of pioneers and experts of the antibiotic industry for the People's Republic of China.

\section{REFERENCES}

Ligon, B.L. (2004). Penicillin: its discovery and early development. Semin Pediatr Infect Dis 15, 52-57.

Richards, A.N. (1964). Production of penicillin in the United States (1941-1946). Nature 201, 441-445.

Chu, C.M., Wong, Y.W., Fan, C.C., and Tang, F.F. (1945). Experimental production of penicillin in China. Chinese Med J 64, 89-101.

Tang, F.F. (1949).The retrospect and prospect of self-production of penicillin in China. Sci World 18, 3-5. (汤飞凡. (1949). 吾国自制 青霉素的回顾与前瞻. 科学世界, 18, 3-5.) 